\title{
Review Article \\ Influence of Physical Activity and Nutrition on Obesity-Related Immune Function
}

\author{
Chun-Jung Huang, ${ }^{1}$ Michael C. Zourdos, ${ }^{1}$ Edward Jo, ${ }^{2,3}$ and Michael J. Ormsbee ${ }^{3}$ \\ ${ }^{1}$ Department of Exercise Science and Health Promotion, Florida Atlantic University, 777 Glades Road, FH11A-126B, \\ Boca Raton, FL 33431, USA \\ ${ }^{2}$ Department of Kinesiology and Health Promotion, California State Polytechnic University, Pomona, Pomona, CA, USA \\ ${ }^{3}$ Department of Nutrition, Food and Exercise Sciences, The Florida State University, Tallahassee, FL, USA
}

Correspondence should be addressed to Chun-Jung Huang; chuang5@fau.edu

Received 31 August 2013; Accepted 19 September 2013

Academic Editors: F. D’Acquisto and A. A. Manfredi

Copyright (C) 2013 Chun-Jung Huang et al. This is an open access article distributed under the Creative Commons Attribution License, which permits unrestricted use, distribution, and reproduction in any medium, provided the original work is properly cited.

Research examining immune function during obesity suggests that excessive adiposity is linked to impaired immune responses leading to pathology. The deleterious effects of obesity on immunity have been associated with the systemic proinflammatory profile generated by the secretory molecules derived from adipose cells. These include inflammatory peptides, such as TNF- $\alpha$, CRP, and IL-6. Consequently, obesity is now characterized as a state of chronic low-grade systemic inflammation, a condition considerably linked to the development of comorbidity. Given the critical role of adipose tissue in the inflammatory process, especially in obese individuals, it becomes an important clinical objective to identify lifestyle factors that may affect the obesity-immune system relationship. For instance, stress, physical activity, and nutrition have each shown to be a significant lifestyle factor influencing the inflammatory profile associated with the state of obesity. Therefore, the purpose of this review is to comprehensively evaluate the impact of lifestyle factors, in particular psychological stress, physical activity, and nutrition, on obesity-related immune function with specific focus on inflammation.

\section{Introduction}

The global epidemic of obesity is irrefutably a major public health issue largely because of its comorbidities, namely, cardiovascular disease, type II diabetes, and cancer. Nevertheless, the prevalence of obesity has drastically escalated by nearly $57 \%$ over the previous two decades $[1,2]$. The National Health and Nutrition Examination Survey (NHANES 20092010 ) reported that $36 \%$ of US adults are currently classified as obese (BMI $\geq 30 \mathrm{~kg} / \mathrm{m}^{2}$ ), while $16 \%$ represent incidences of severe cases (BMI $\geq 35 \mathrm{~kg} / \mathrm{m}^{2}$ ) [2]. Based on projections derived from previous NHANES data, $86 \%$ of U.S adults will be overweight (BMI $\geq 25 \mathrm{~kg} / \mathrm{m}^{2}$ ) or obese (obesity accounting for $51.1 \%$ ) by 2030 if this epidemiological trend remains unresolved [3-5].

Over the past two decades, adipose tissue has been established as a multifunctional organ playing a critical role not only in lipid/energy storage but also in endocrine and immune functions [6-8]. The confirmed presence of secretory molecules derived from adipocytes, such as proinflammatory cytokines (e.g., tumor necrosis factor-alpha [TNF- $\alpha$ ] and interleukin-6 [IL-6]), constitutes the unique endocrine function of adipose and provides valuable pathophysiological insight regarding obesity and its comorbidities [7]. During unhealthy weight gain, the influx and storage of excess lipids in adipocytes perturbs normal cell function, which consequently induces the overexpression and hyper-secretion of inflammatory peptides into circulation [9]. As a result, obesity is now recognized as a state of low-grade systemic inflammation characterized by high circulating levels of inflammatory molecules, such as TNF- $\alpha$, IL- 6 , and C-reactive protein (CRP) $[10,11]$. Due to the deleterious effects of systemic inflammation on multiple organ tissues, unhealthy weight gain is associated with high risk of developing serious health conditions, such as type II diabetes and cardiovascular disease $[7,12]$. Given the involvement of adipose tissue in 
the inflammatory process, especially in excessive states, it becomes an important clinical objective to identify lifestyle factors that may affect the obesity-immune system dynamic. For instance, stress, physical activity, and nutrition have each shown to be significant lifestyle factors influencing the inflammatory profile associated with the state of obesity [1315]. Of particular interest, it is well documented that chronic inflammation is also highly correlated to nutritional factors such as the type and amount of carbohydrates, proteins and fats that are consumed in the diet [16-18]. Therefore, the purpose of this review is to comprehensively evaluate the impact of lifestyle factors, in particular psychological stress, physical activity, and nutrition, on obesity-related immune function with special focus on inflammation.

\section{Stress and Obesity}

Stress in the body is established through some type of stressor(s), either physical or psychological. When stimulated, the human body responds in a complex manner, incorporating the intertwined activity of the endocrine and nervous systems (hypothalamic-pituitary-adrenal [HPA] and sympathoadrenal [SA] axes). Stress hormones such as cortisol from HPA axis and catecholamines (epinephrine (EPI) and norepinephrine (NE)) from the SA axis have been shown to alter immune cell responses, and this important immune system response coordinates a number of the body's adaptations to the stressor. Notably, elevations in stress hormones (cortisol and catecholamines) are thought to have detrimental effects on the immune system, leading to an imbalance between innate (immediate antigen-nonspecific defense) and adaptive immunity (specific response to a particular foreign antigen creating immunological memory) via the release of immune mediators such as cytokines [19]. In response to acute stress, the innate immune promptly prepares to provide immune protection followed by adaptive immunity when exposed to repeated or prolonged stress, whereas chronic stress can suppress these immune defenses. This stress-immune interaction is an important antiviral defense and fosters the elimination of invading microorganisms [20,21].

Research has shown that stress induces changes in immune cell distribution [22-25], which ensures that the body's immune response is efficient or elicits an effective immunoprotection. An appropriate distribution of peripheral immune cells provides for the performance of surveillance and effector functions of the immune system [26]. The release of catecholamines and cortisol in response to stressors (physical or psychological) can mediate changes in the immune cell distribution $[27,28]$. In response to acute stress, immune response is primarily regulated by catecholamines [24]. This is further supported by other studies demonstrating transient immune cell redistribution via betaadrenergic activation following acute mental stress [23, 27, $29,30]$. Specifically in response to exercise, monocytes and NK cells (innate immunity) exhibit the greatest fluctuation followed by CD3 + T cells and CD19+ B cells (adaptive immunity) [31-33]. These alterations in immune cells have been shown to correspond with the release of catecholamines [34].
In addition, our laboratory recently found that following a combined physical and psychological stress, NE area-underthe-curve (AUC) was negatively correlated with the percentage of CD19+ B cells, and heart rate (HR) was negatively associated with the percentage change in the CD4/CD8 ratio [35]. These elevations in NE and HR simultaneously in response to the dual challenge suggest greater sympathetic activation that, in turn, could possibly explain the alteration in the distribution of lymphocyte subsets, resulting in ineffective cell-mediated immune responses [36, 37]. Therefore, these findings indicate that acute stress enhances innate immunity and possibly suppresses adaptive immunity, and these alterations can be likely enhanced at higher intensities of physical stress. The appropriate redistribution of immune cells in response to acute stressors is imperative to an effective and efficient immune response in preparation for potential invaders and injury [26, 38]. However, when exposed to chronic stress, immunoprotection can be suppressed by reducing immune cell number, function (cytotoxicity), and proliferation, thereby promoting susceptibility to diseases $[39,40]$.

Obesity is considered a chronic inflammatory condition that enhances the risk of numerous inflammatory diseases, including diabetes and cardiovascular disease (CVD). These obesity-attributable illnesses have been discovered to have a strong association with inflammatory parameters in plasma such as proinflammatory cytokines (TNF- $\alpha$ and IL-6) [41, 42]. In addition to plasma inflammatory mediators, the circulating mononuclear cells in obese individuals may be more readily stimulated to produce inflammatory cytokines [43]. Interestingly, along with physical illnesses, obesity is associated with job-associated stress and psychosocial disorders such as depression and chronic anxiety [44-46]. These stress-related disorders have been found to lead to increased risk of CVD and mortality in obese patients [47].

Chronic stress has been shown to be associated with disturbances of the HA and SA axes and is linked to abdominal adiposity [48]. In response to acute stress, elevated cortisol levels are associated with high central adiposity [49-51]. Furthermore, studies have demonstrated an increase in SA axis reactivity in obesity patients [52-54]. This occurrence seems to be pivotal to understand how stress may upregulate the inflammatory conditions in obese individuals. Recently, studies have shown that obese subjects exhibit higher proinflammatory cytokine production such as IL-6 in plasma and ex vivo compared with normal-weight subjects in response to acute mental stress $[50,55]$. Although chronically elevated cortisol is thought to have deleterious effects on the immune system, a suppressive effect of immune regulation has been shown in response to acute stressors [56]. Importantly, Wirtz et al. [57] have revealed that individuals with higher body mass index demonstrated lower glucocorticoid sensitivity, resulting in a diminished ability to inhibit production of TNF- $\alpha$ following acute mental stress.

In addition, $\beta$-adrenergic receptors have been shown to mediate catecholamine-induced decreases in proinflammatory cytokines $[58,59]$. Stress has been demonstrated to downregulate beta-adrenergic receptor expression and functions on monocytes and NK cells, resulting in the elevation 
of TNF- $\alpha$ and IL-6 [46]. These are key proinflammatory cytokines involved in CVD, chronic anxiety, and depression [60]. Furthermore, previous studies demonstrated that increased tension-anxiety, a subscale of the Profile of Mood States (POMS), is correlated with the downregulation of $\beta$ adrenergic receptors [61]. Individuals with high life stress and hostility have less lymphocyte $\beta$-adrenergic sensitivity [62]. Taken together, these findings suggest that obesity could diminish the inhibitory effect of $\beta$-adrenergic receptors in response to acute stress, resulting in a greater release of proinflammatory cytokines $[50,55]$. Thus far, it has been discovered that obese individuals have reduced $\beta$-adrenergic receptor density [63] and higher plasma NE and EPI concentrations [64]. Hence, the investigation of mechanisms of $\beta$-adrenergic receptor regulation to stress may provide insight into the role of psychoneuroimmunological processes in obese populations' health and disease.

Although the underlying mechanisms contributing to the relationship of the stress response, obesity, and proinflammatory cytokines remain to be determined, elevated levels of leptin have recently been implicated as a contributing factor that links acute stress to inflammation. Leptin, an adipocytederived hormone, plays an important role in metabolism, adiposity, and vascular inflammation and has been implicated in the development of coronary heart disease [65]. In vitro stimulation of cultured human endothelial cells with leptin has induced an increased accumulation of levels of proinflammatory mediator (e.g., monocyte chemotactic protein-1) via activation of nuclear factor-kappa B [66]. Interestingly, recent research has shown that people who undergo acute mental stress demonstrate increases in leptin levels, and these increases are positively correlated with waist circumference $[67,68]$. Brydon et al. [68] also showed that a positive correlation between basal circulating leptin and IL-6 exists in response to mental stress. These findings suggest that leptin may partially contribute to inflammatory response following acute stress. Future investigation should attempt to understand the mechanisms contributing to the relationship between obesity and proinflammatory reactivity to stress. In turn, an understanding of how the mind and body interact and impact health can directly influence how we develop targeted treatments, such as exercise-training and weight loss programs, as therapeutic interventions for obesity-associated cardiovascular, chronic infectious, and inflammatory neuropsychiatric diseases.

\section{Physical Activity and Immune Function}

Physical activity has long been associated with improvements in aerobic capacity [69], strength [70], muscle growth [71], and body composition [70]. However, it is now widely accepted that chronic physical activity enhances immune function and attenuates the likelihood of chronic disease, such as CVD, diabetes, and obesity [72, 73]. Initially, unaccustomed exercise places a stressor on the body resulting in fatigue [74]; however, once the recovery process occurs, beneficial adaptations are the result. In fact, fit individuals (those who partake in regular physical activity) have a lower incidence of infection compared to inactive and sedentary individuals $[75,76]$, suggesting that physical activity may improve the immune response. Moreover, these benefits to immune function in relation to regular exercise include decreased levels of proinflammatory cytokines TNF- $\alpha$ [77], IL-6 [78], and CRP [79] along with an increase in the antiinflammatory marker (IL-10) [78]. Additionally, exercise is associated with decreased levels of depression [80]. To fully comprehend the positive benefits of exercise to immune function it is necessary to examine the stress and recovery response to exercise. Additional insight into how exercise affects acute and chronic inflammation is necessary to understand the importance of exercise as an antagonist to the current obesity epidemic.

3.1. Exercise and the Stress Response. Intense exercise training places a stimulus on the body often resulting in myofiber damage, muscle soreness, and edema [81]. This damaging effect particularly occurs in novice trainees who are stressed by an unfamiliar stimulus. This initial fatigue in response to a new stimulus is described in Hans Seyle's landmark work, the general adaptations syndrome (GAS) [74], as the "alarm reaction stage." Following the initial alarm response, the GAS explains that once recovery takes place, an individual enters the stage of resistance, indicating the capability of undertaking further stress. The onset of the stage of resistance signifies the adaptation to the initial stress realized in the alarm stage. This concept of initial fatigue and recovery is similar to the repeated bout effect (RBE), which states that performing the same exercise stimulus within 6 months of the initial bout results in an attenuated level of myofiber damage [81]. Consequently, the incurred adaptation is specific to the task performed in the initial exercise bout. This concept of specificity is otherwise known as the specific adaptations to imposed demands (SAID) principle, which states that individuals adapt to the specific stressor placed upon them to become more fit for living conditions [82]. Although initial fatigue leads to long-term adaptation without programmed rest and variation to exercise-training volume and intensity, tissue repair may not fully transpire and overtraining syndrome may develop [83]. Moreover, lack of ample recovery for tissue repair may result in chronic inflammation and central fatigue potentially having deleterious effects on exercise performance. Furthermore, a state of chronic inflammation, which impairs immune function, may contribute to an increased probability of obesity, CVD, and diabetes.

3.2. Acute and Chronic Inflammation. When dissecting the subsequent effects of the inflammatory response, it is necessary to understand that inflammation can be both acute and chronic in nature [84]. Acute inflammation is an immediate response to stress and may not necessarily be indicative of long-term adaptations. To illustrate, acute stress hormone response, such as cortisol, has increased significantly in response to high-volume resistance training [85]. However, long-term exercise training of two years in length has resulted in decreased resting cortisol concentrations [86]. Thus, chronic exercise training appears to reduce resting 
cortisol levels. Therefore, acute elevations in markers of stress signify an immediate stress response; however, long-term adaptations to physical activity appear to favor parasympathetic dominance.

3.3. Exercise and Acute Inflammation. A typical acute response to an infection, stressor, or immune system stimulator lipopolysaccharide (LPS) is the elevation of the proinflammatory cytokine TNF- $\alpha$ [87]. In rats that were exercised to exhaustion (an average of 102 minutes), an attenuated TNF- $\alpha$ response was measured compared to the response in nonexercised rats when administered with LPS for up to 6 hours [87]. In agreement, in human data, healthy men who performed aerobic exercise to exhaustion prior to the infusion of LPS exhibited lower levels of TNF- $\alpha$ compared to a non-exercising group [77]. Likewise, Nosaka and Clarkson [88] reported no increase in plasma levels of TNF- $\alpha$ following a bout of damaging resistance training of the elbow flexors. Interestingly, TNF- $\alpha$ levels have been reported to be significantly elevated in obese populations [89, 90]. Indeed, TNF- $\alpha$ has been established to be associated with insulin resistance, leading to obesity [91]. Ultimately, both aerobic and resistance exercise may be effective in attenuating acute inflammatory responses, which might have significant implications to preventing obesity.

3.4. Exercise and Chronic Inflammation. Numerous studies have been conducted on the relationship between exercise and concentrations of CRP [79, 92, 93]. These studies all demonstrate an inverse relationship between CRP concentrations and physical activity [92]. Further, physical fitness measured by maximal oxygen consumption $\left(\mathrm{VO}_{2} \max \right)$ is also inversely related to CRP concentrations [94]. Data also indicates that active older men (i.e., exercising 4 days/wk) have lower levels of IL- 6 and greater levels of IL-10 when compared to older men who perform a low amount of physical activity (i.e., not active most days of the week) [78].

Moreover, multiple studies show that lifestyle interventions with exercise impact the inflammatory response [9598]. Balagopal et al. [95] reported that obese adolescents who underwent a 3-month lifestyle intervention of enhanced physical activity and nutrition habits had decreased body fat percentage, insulin resistance, CRP, and IL-6. Additionally, nine months of endurance training in 14 individuals preparing for a marathon resulted in decreased levels of CRP [92]. Likewise, an exercise intervention of 3 years, which gave detailed advice in regard to physical activity, in 60 obese women resulted in weight loss along with decreased levels of TNF- $\alpha$ [99]. In fact, an 8-week exercise-training program consisting of 4 days/wk of cycling between 40 and $50 \% \mathrm{VO}_{2}$ peak did not affect insulin sensitivity or CRP levels despite improvements in aerobic fitness and endothelial function [96]. One possible explanation for these conflicting results is that the intervention duration of 8 weeks was too short to elicit changes in insulin sensitivity and CRP levels. Ultimately, it seems that long-term exercise interventions (greater than 8 weeks) are effective in reduce the inflammation response and improve physical fitness.
3.5. Summary. Obesity is a chronic inflammatory condition, which enhances the risk of CVD and is associated with various inflammatory cytokines (TNF- $\alpha$ and IL-6). When introduced as a new stressor, exercise acutely increases catabolic responses [85], resulting in muscle fatigue [74]. However, research indicates that regular participation in exercise leads to decreased systemic inflammation [93]. Indeed, Colbert et al. [72] related higher levels of physical activity to lower levels of IL-6 and CRP. Furthermore, exercise is beneficial during the aging process to decrease catabolic hormone responses [100]. Consequently, exercise seems to provide significant benefits that enhance immune function and decrease inflammation. Thus, exercise is recommended as an effective strategy to positively alter obesity-related immune function.

\section{Nutrition and Inflammation}

\subsection{Macronutrients: Quality and Quantity}

4.1.1. Energy Content. Chronic inflammation is influenced by energy balance. Acute overconsumption of energy has consistently resulted in increases in markers of inflammation [101]. These increases occur with or without weight gain, suggesting that chronic inflammation in overweight or obese individuals may be strongly influenced by caloric load and not necessarily the primary result of increased adiposity. This may also help to explain the prevalence of chronic disease in the Western world where diets often include calorie-dense foods (e.g., "fast food"). Conversely, caloric restriction and/or fasting can also result in increases in inflammation [102]. These findings suggest maintenance of energy balance as an important factor in the prevention of systemic inflammation. Interestingly, outside of energy balance, the type of macronutrients that we consume also plays a pivotal role in whole-body inflammation.

4.1.2. Carbohydrates. Carbohydrates $(\mathrm{CHO})$ can dramatically influence whole-body inflammation. In addition, there are many factors that affect the inflammatory potential of $\mathrm{CHO}$ intake including glycemic index (GI), glycemic load (GL), and dietary fiber. The degree to which a CHO increases the blood sugar response (high-GI equals greater increases in blood sugar) will influence the inflammatory response. In fact, GI has consistently shown a positive correlation with biomarkers of whole-body inflammation. Specifically, markers of inflammation increase acutely following a high GI meal [103]. Of note, markers of inflammation either decline or remain unchanged following low-GI meals [104]. This discrepancy may be a function of GL, the product of dietary GI, and quantity of $\mathrm{CHO}$ actually eaten, as consumption of a large quantity of low-GI food has been shown to increase markers of inflammation to a similar degree as to the consumption of a small quantity of high-GI food [105]. However, data on the relationship between GL and inflammation are conflicting. Although some studies have shown a positive correlation between dietary GL and markers of inflammation (i.e., C-reactive protein, CRP) [106, 107], others have failed to report a significant association [108]. This divergence may 
be due to differences in energy content of the diets in GL studies, which, as discussed above, has been shown to have a strong relationship with inflammation [109]. Many GL studies compare varying dietary $\mathrm{CHO}$ amounts while simultaneously limiting calories to encourage weight loss. Therefore, these alterations may go against each other and possibly explain the confounding results.

Increased consumption of refined carbohydrates in the modern diet has not only led to increased consumption of high-GI diets but also reduced intake of dietary fiber. This low fiber intake may explain the increased prevalence of chronic inflammation and disease as numerous studies have reported an inverse relationship between fiber intake and CRP [110]. Of interest, the anti-inflammatory effects of fiber appear to hold true for both dietary fiber and fiber supplements [111]. Moreover, this relationship may also hold true for insoluble fibers, which have been shown to positively affect immune function [112]. Dietary fiber may also influence inflammation through its mediating effects on glycemia. In one lifestyle intervention study on a representative sample of Italian adults, blood CRP concentrations were lowered along with fasting blood glucose in response to increased fiber intake, independent of weight loss [113]. Thus, perhaps by mediating the absorption of nutrients and modulating changes in blood sugar, fiber effectively reduces inflammation.

4.1.3. Fats. The inflammatory potential of fat is a function of the type of fat being consumed. Numerous studies have implicated saturated fats (SFAs) as inflammatory agents. SFAs, which are commonly found in processed meat, refined grain, and/or fried foods, have been shown to increase markers of inflammation such as CRP, IL-6, and E-selectin, a vascular adhesion molecule [114]. A strong correlation between SFAs and CRP can be found in the National Health and Nutrition Education Survey (NHANES 99-00) [115]. Furthermore, Arya et al. [116] reported that among other dietary nutrients, SFA levels were the most important predictor of CRP levels. However, it should be noted that some studies have failed to show a correlation [117] or, in some cases, have even shown a slight negative correlation between SFA and CRP levels [118]. This discrepancy may be due to the population studied and confounding variables such as other nutrients included in the diet, physical activity, and the population studied. Trans fats (TFA), fatty acids containing one double bond created via hydrogenation of vegetable oils, which are found in foods such as butter, margarine, milk fat, and fried foods, may also increase markers of inflammation. In the Nurses' Health Study, a strong correlation was shown between TFA levels and inflammatory biomarkers of CRP, IL-6, and E-selectin [119]. This may explain the strong connection between serum TFA levels and coronary heart disease [120].

Conversely, monounsaturated fatty acids (MUFAs) and polyunsaturated fatty acids (PUFAs) have an inverse relationship with the inflammatory biomarkers. Levels of certain PUFAs such as omega-3 fatty acids, common in cold-water fish, are consistently found to have an inverse relationship with IL-6 [121]. The effects of other common PUFAs such as omega- 6 fatty acids are less clear. Inflammatory and noninflammatory effects have been reported with omega- 6 consumption [122]. Indeed, the effectiveness of PUFAs in reducing markers of inflammation may lie in the ratio between omega- 3 and omega- 6 PUFAs. It has also been suggested that a higher ratio of omega- 3 to omega- 6 PFAs increases the anti-inflammatory potential of these fats [123]. MUFAs also appear to be anti-inflammatory as several studies $[124,125]$, but not all [118], have reported an inverse relationship between MUFA levels and inflammatory markers. Stronger evidence for this inverse relationship is found specifically between olive oil consumption, which contains high levels of MUFAs, and systemic inflammatory markers [126].

4.1.4. Protein. The effects of proteins on inflammation seem to vary depending on the source of the protein. Red meat is typically considered as proinflammatory. This is likely due to the association between high dietary red meat intake and both coronary heart disease [127] and type II diabetes [128]. However, evidence from studies on lean red meat has failed to show any increase in markers of inflammation [129]. This suggests that the quality of the meat may be more indicative of its inflammatory potential. Indeed, consuming processed meat (e.g., bacon, hamburger, and sausage) seems to increase the risk of type II diabetes, which is associated with increased whole-body inflammation [130].

Inflammation from protein ingestion may also vary between meat-based, plant-based, and milk-based proteins. In a study from Denmark, obese participants were fed a single high-fat meal containing 4 different sources of protein: fish (cod), whey isolate, gluten, or casein. Serum levels of inflammatory cytokines were monitored in the 4 hours following the meal. Cod protein and gluten resulted in a blunted increase in markers of inflammation versus the whey meal but were not different from the casein meal [131]. Therefore, consuming cod protein and/or plant-based protein may be beneficial for whole-body inflammation relative to some milk-based proteins (whey). Evidence also exists to support the use of soy protein to blunt inflammation. In fact, reductions in markers of inflammation have been shown with consumption of soy [132], soybean oil [133], and soy nuts [134]. More data is needed, however, before a definitive conclusion can be made for which types of proteins may work best to reduce wholebody inflammation.

\subsection{Micronutrients/Antioxidants}

4.2.1. Flavonoids. Flavonoids, naturally occurring antioxidant, commonly found in foods such as onions, apples, grapes, berries, and cocoa, are anti-inflammatory agents. Common flavonoids such as quercetin, kaempferol, malvidin, peonidin, daidzein, and genistein have been reported to have an inverse relationship with CRP [135].

4.2.2. Carotenoids. Carotenoids are the natural pigments that give many fruits and vegetables their distinctive bright colors. These are found in abundance in oranges, sweet potatoes, 
kale, and spinach. Carotenoids such as alpha-carotene, betacarotene, and lutein seem to have anti-inflammatory potential. In fact, participants of one study with the highest serum levels of alpha-carotene were significantly less likely to have high levels of IL-6. Interestingly, the opposite was also found to be true where low levels of various carotenoids in the blood were associated with increased levels of IL-6 [136]. Furthermore, another study reported a potentially protective effect of lutein and lycopene against atherosclerosis, which the authors report to be likely a result of a reduction in inflammatory markers [137].

4.2.3. Magnesium. Magnesium, found typically in whole grain, green leafy vegetables, nuts, and legumes, may be one of the most effective agents for combatting chronic inflammation. Numerous studies have reported the inverse relationship between magnesium intake and CRP and IL-6 [119, 138], in some cases in a dose-dependent manner [138].

4.2.4. Vitamins. Vitamins, found commonly in fruits and vegetables, are essential to immune function and are thus a necessary impediment to excessive inflammation. Numerous vitamins such as vitamins $\mathrm{C}, \mathrm{E}, \mathrm{A}, \mathrm{B} 6$, and riboflavin each have been associated with reduced cytokine production (e.g., IL-6) [139].

\subsection{Whole Unprocessed Foods}

4.3.1. Fish. In general, consumption of fish has been linked to various health benefits, particularly heart health [140]. Some of these health benefits may be due to reductions in markers of inflammation [141]. This seems likely as certain fish, particularly cold-water fish like salmon and mackerel, contain high levels of PUFAs like omega-3 fatty acids, which as discussed above, likely have anti-inflammatory effects. Indeed, the anti-inflammatory nature of fish seems to be a direct result of PUFA content as numerous studies on fish oil supplements (high in omega-3 PUFAs) have reported reductions in markers of whole-body inflammation [142, 143]. In agreement, using salmon fed 3 different diets to manipulate the omega-3 fatty acid content of the fish, it was found that only the participants consuming salmon containing the highest levels of omega-3s saw reductions in IL-6 [144].

4.3.2. Fruits and Vegetables. A large body of research exists documenting the many health benefits of consuming fruits and vegetables [140]. Moreover, the anti-inflammatory effects of consuming fruit and vegetables are well documented [145, 146]. This is no surprise considering that fruits and vegetables contain high concentrations of dietary fiber, flavonoids, carotenoids, and vitamins, which have all been associated with reductions in markers of inflammation, as discussed above. Beyond these ingredients, certain fruits contain particular compounds such as anthocyanins and bromelain, which may also be anti-inflammatory [147-151]. Anthocyanins are the pigments found in fruits such as strawberries, cherries, blackberries, and black currants. Research has indicated the potential of anthcyanins to inhibit cancer formation in rodents [147]. This finding could be the result of reported anti-inflammatory properties of anthocyanins. A recent study on participants with high blood cholesterol levels reported that consumption of an anthocyanin supplement twice daily for 24 weeks resulted in reductions in CRP and other markers of systemic inflammation [148].

Bromelain is a proteolytic enzyme found primarily in pineapples. Among many other therapeutic benefits (e.g., improved endothelial function, enhanced absorption of antibiotic drugs, and inhibition of tumor cell growth), bromelain is an effective anti-inflammatory agent [149]. These anti-inflammatory properties have been observed in vitro via its modulating effect on certain inflammatory cytokines [150]. The benefits are also apparent in clinical trials which report the effectiveness of bromelain for treating certain inflammation-derived diseases/conditions (e.g., osteoarthritis) [151].

\subsection{Beverages}

4.4.1. Tea/Coffee. Tea consumption is associated with reduced markers of inflammation. In fact, after 6 weeks of black tea consumption in healthy men, there was a reduction in CRP and platelet aggregation [152]. Green tea may have similar properties as it has been indicated to be an effective antioxidant in vitro [153]. However, the effectiveness of green tea at reducing markers of inflammation like CRP in clinical trials is less clear. Studies examining 1-month to green tea consumption on healthy males [154] and male smokers [155] have failed to report an effect on CRP levels.

The effects of coffee consumption on inflammation are equivocal. Some studies have reported anti-inflammatory effects [156], while others have reported no effects at all [157]. This could be due to genetic factors as a recent study revealed a genetic polymorphism affecting one's responsiveness to caffeine [158]. Because caffeine may have anti-inflammatory properties [159], the effectiveness of coffee as an antiinflammatory agent may be mediated by one's responsiveness to caffeine. While speculative, the impact of physical activity and other lifestyle factors likely plays a critical role in the overall anti-inflammatory response to these nutrients.

4.4.2. Alcohol. The effectiveness of alcohol at reducing or preventing inflammation seems to depend on the amount consumed. While excessive consumption and/or binge drinking is known to have many adverse health outcomes including increased inflammation [160], moderate intake (e.g., $~ 150 \mathrm{~mL}$ of wine per day) of alcohol seems to reduce markers of inflammation in various populations [161]. The degree to which these markers are reduced may depend on the source of alcohol. Red wine, for example, has consistently been reported to have anti-inflammatory effects [162], leading to speculation that these effects may simply be derived from grape-derived antioxidants in the wine. However, other alcoholic beverages such as beer and liquor have also been found to have anti-inflammatory properties [163]. Overall, this implicates small doses of alcohol to be anti-inflammatory. 
In support, no effects on markers of inflammation were reported with consumption of nonalcoholic beer [164].

4.5. Herbs and Spices. Many herbs and spices have been reported to have anti-inflammatory effects [165]. For example, cloves, garlic, curcumin, cinnamon, fennel, ginger, fenugreek, ginseng, and capsaicin have all shown to be effective at reducing or preventing inflammation. However, the full explanation of these herbs and spices with regard to inflammation has already been conducted [165].

4.6. Summary. It is apparent that nutrition plays a critical role in the whole-body inflammatory response. Indeed, overconsumption of highly processed foods and lack of fruit and vegetable intake are common in North America [166] and parallel the increase in obesity and other inflammatoryassociated diseases. The literature suggests that an energybalanced nutrient intake combined with low-GI and low-GL $\mathrm{CHO}$, higher intake of omega-3 PUFAs, a focus on lean meat consumption, and a greater intake of fruits and vegetables may provide the ideal anti-inflammatory environment. A nutritional program that offers these macronutrient choices would also likely supply beneficial vitamins, minerals, and other micronutrients to aid in the anti-inflammatory process.

\section{Conclusion}

It is evident that lifestyle factors, such as stress, physical activity, and nutrition, both cooperatively and independently influence the inflammatory profile associated with excessive adiposity and may play a critical role in the development or prevention of obesity-related comorbidity. Chronic stress, sedentary behaviors, and overnutrition are lifestyle factors conducive to obesity and systemic inflammation. On the other hand, stress reduction and proper nutritional and exercise programming have each shown to be beneficial in ameliorating the inflammatory processes associated with obesity whether they are directly or indirectly involved with weight loss management.

\section{Conflict of Interests}

All authors declare that they have no conflict of interest.

\section{Acknowledgments}

The authors would like to thank Dan Baur and Aaron Slusher for their contributions to this paper.

\section{References}

[1] "Prevalence of obesity in the United States, 2009-2010," 2012, http://www.cdc.gov/nchs/data/databriefs/db82.htm\#Ref6.

[2] K. M. Flegal, D. Carroll, B. K. Kit, and C. L. Ogden, "Prevalence of obesity and trends in the distribution of body mass index among US adults, 1999-2010," Journal of the American Medical Association, vol. 307, no. 5, pp. 491-497, 2012.
[3] Y. Wang, M. A. Beydoun, L. Liang, B. Caballero, and S. K. Kumanyika, "Will all Americans become overweight or obese? Estimating the progression and cost of the US obesity epidemic," Obesity, vol. 16, no. 10, pp. 2323-2330, 2008.

[4] V. A. Catenacci, J. O. Hill, and H. R. Wyatt, "The obesity epidemic," Clinics in Chest Medicine, vol. 30, no. 3, pp. 415-444, 2009.

[5] E. A. Finkelstein, O. A. Khavjou, H. Thompson et al., "Obesity and severe obesity forecasts through 2030," American Journal of Preventive Medicine, vol. 42, no. 6, pp. 563-570, 2012.

[6] I. Falcão-Pires, P. Castro-Chaves, D. Miranda-Silva et al., "Physiological, pathological and potential therapeutic roles of adipokines," Drug Discovery Today, vol. 17, no. 15, pp. 880-889, 2012.

[7] Z. Y. Li, P. Wang, and C. Y. Miao, "Adipokines in inflammation, insulin resistance and cardiovascular disease," Clinical and Experimental Pharmacology and Physiology, vol. 38, no. 12, pp. 888-896, 2011.

[8] R. S. Ahima and J. S. Flier, "Adipose tissue as an endocrine organ," Trends in Endocrinology and Metabolism, vol. 11, no. 8, pp. 327-332, 2000.

[9] A. S. Greenberg and M. S. Obin, "Obesity and the role of adipose tissue in inflammation and metabolism," American Journal of Clinical Nutrition, vol. 83, supplement 2, pp. 461S-465S, 2006.

[10] J. S. Yudkin, C. D. A. Stehouwer, J. J. Emeis, and S. W. Coppack, "C-reactive protein in healthy subjects: associations with obesity, insulin resistance, and endothelial dysfunction: a potential role for cytokines originating from adipose tissue?" Arteriosclerosis, Thrombosis, and Vascular Biology, vol. 19, no. 4, pp. 972-978, 1999.

[11] G. Fantuzzi, "Adipose tissue, adipokines, and inflammation," Journal of Allergy and Clinical Immunology, vol. 115, no. 5, pp. 911-920, 2005.

[12] G. Fantuzzi and T. Mazzone, "Adipose tissue and atherosclerosis: exploring the connection," Arteriosclerosis, Thrombosis, and Vascular Biology, vol. 27, no. 5, pp. 996-1003, 2007.

[13] B. K. Pedersen and M. A. Febbraio, "Muscles, exercise and obesity: skeletal muscle as a secretory organ," Nature Reviews Endocrinology, vol. 8, no. 8, pp. 457-465, 2012.

[14] S. Hickling, J. Hung, M. Knuiman, M. Divitini, and J. Beilby, "Are the associations between diet and C-reactive protein independent of obesity?" Preventive Medicine, vol. 47, no. 1, pp. 71-76, 2008.

[15] S. Benson, P. C. Arck, S. Tan et al., "Effects of obesity on neuroendocrine, cardiovascular, and immune cell responses to acute psychosocial stress in premenopausal women," Psychoneuroendocrinology, vol. 34, no. 2, pp. 181-189, 2009.

[16] H. K. Choi, "Dietary risk factors for rheumatic diseases," Current Opinion in Rheumatology, vol. 17, no. 2, pp. 141-146, 2005.

[17] A. Margioris, "Fatty acids and postprandial inflammation," Current Opinion in Clinical Nutrition and Metabolic Care, vol. 12, no. 2, pp. 129-137, 2009.

[18] S. E. Kasim-Karakas, A. Tsodikov, U. Singh, and I. Jialal, "Responses of inflammatory markers to a low-fat, highcarbohydrate diet: effects of energy intake," American Journal of Clinical Nutrition, vol. 83, no. 4, pp. 774-779, 2006.

[19] I. J. Elenkov and G. P. Chrousos, "Stress hormones, proinflammatory and antiinflammatory cytokines, and autoimmunity," Annals of the New York Academy of Sciences, vol. 966, pp. 290303, 2002. 
[20] M. Paulose, B. L. Bennett, A. M. Manning, and K. Essani, "Selective inhibition of TNF- $\alpha$ induced cell adhesion molecule gene expression by tanapox virus," Microbial Pathogenesis, vol. 25, no. 1, pp. 33-41, 1998.

[21] P. H. Black, “The inflammatory consequences of psychologic stress: relationship to insulin resistance, obesity, atherosclerosis and diabetes mellitus, type II," Medical Hypotheses, vol. 67, no. 4, pp. 879-891, 2006.

[22] P. J. Mills, J. E. Dimsdale, R. A. Nelesen, and E. Dillon, "Psychologic characteristics associated with acute stressorinduced leukocyte subset redistribution," Journal of Psychosomatic Research, vol. 40, no. 4, pp. 417-423, 1996.

[23] G. Willemsen, D. Carroll, C. Ring, and M. Drayson, "Cellular and mucosal immune reactions to mental and cold stress: associations with gender and cardiovascular reactivity," Psychophysiology, vol. 39, no. 2, pp. 222-228, 2002.

[24] T. Isowa, H. Ohira, and S. Murashima, "Reactivity of immune, endocrine and cardiovascular parameters to active and passive acute stress," Biological Psychology, vol. 65, no. 2, pp. 101-120, 2004.

[25] M. H. Burleson, W. B. Malarkey, J. T. Cacioppo et al., "Postmenopausal hormone replacement: effects on autonomic, neuroendocrine, and immune reactivity to brief psychological stressors," Psychosomatic Medicine, vol. 60, no. 1, pp. 17-25, 1998.

[26] F. S. Dhabhar, A. H. Miller, B. S. McEwen, and R. L. Spencer, "Effects of stress on immune cell distribution: dynamics and hormonal mechanisms," Journal of Immunology, vol. 154, no. 10, pp. 5511-5527, 1995.

[27] R. J. Benschop, M. Schedlowski, H. Wienecke, R. Jacobs, and R. E. Schmidt, "Adrenergic control of natural killer cell circulation and adhesion," Brain, Behavior, and Immunity, vol. 11, no. 4, pp. 321-332, 1997.

[28] S. G. Rhind, P. N. Shek, and R. J. Shephard, "The impact of exercise on cytokines and receptor expression," Exercise Immunology Review, vol. 1, no. 1, pp. 97-148, 1995.

[29] R. J. Benschop, F. P. Nijkamp, R. E. Ballieux, and C. J. Heijnen, "The effects of $\beta$-adrenoceptor stimulation on adhesion of human natural killer cells to cultured endothelium," British Journal of Pharmacology, vol. 113, no. 4, pp. 1311-1316, 1994.

[30] R. J. Benschop, M. Rodriguez-Feuerhahn, and M. Schedlowski, "Catecholamine-induced leukocytosis: early observations, current research, and future directions," Brain, Behavior, and Immunity, vol. 10, no. 2, pp. 77-91, 1996.

[31] S. Hong and P. J. Mills, "Effects of an exercise challenge on mobilization and surface marker expression of monocyte subsets in individuals with normal vs. elevated blood pressure," Brain, Behavior, and Immunity, vol. 22, no. 4, pp. 590-599, 2008.

[32] S. G. Rhind, "Effects of moderate endurance exercise and training on in vitro lymphocyte proliferation, interleukin-2 (IL2) production, and IL-2 receptor expression," European Journal of Applied Physiology and Occupational Physiology, vol. 74, no. 4, pp. 348-360, 1996.

[33] N. M. Moyna, G. R. Acker, J. R. Fulton et al., "Lymphocyte function and cytokine production during incremental exercise in active and sedentary males and females," International Journal of Sports Medicine, vol. 17, no. 8, pp. 585-591, 1996.

[34] V. M. Natale, I. K. Brenner, A. I. Moldoveanu, P. Vasiliou, P. Shek, and R. J. Shepard, "Effects of three different types of exercise on blood leukocyte count during and following exercise," Sao Paulo Medical Journal, vol. 121, no. 1, pp. 9-14, 2003.
[35] C. J. Huang, H. E. Webb, R. S. Garten, G. H. Kamimori, and E. O. Acevedo, "Psychological stress during exercise: lymphocyte subset redistribution in firefighters," Physiology and Behavior, vol. 101, no. 3, pp. 320-326, 2010.

[36] K. Kimura, T. Isowa, H. Ohira, and S. Murashima, “Temporal variation of acute stress responses in sympathetic nervous and immune systems," Biological Psychology, vol. 70, no. 2, pp. 131139, 2005.

[37] K. Kimura, T. Isowa, M. Matsunaga, S. Murashima, and $H$. Ohira, "The temporal redistribution pattern of NK cells under acute stress based on CD62L adhesion molecule expression," International Journal of Psychophysiology, vol. 70, no. 1, pp. 6369, 2008.

[38] F. S. Dhabhar and B. S. McEwen, "Acute stress enhances while chronic stress suppresses cell-mediated immunity in vivo: a potential role for leukocyte trafficking," Brain, Behavior, and Immunity, vol. 11, no. 4, pp. 286-306, 1997.

[39] J. K. Kiecolt-Glaser, R. Glaser, S. Gravenstein, W. B. Malarkey, and J. Sheridan, "Chronic stress alters the immune response to influenza virus vaccine in older adults," Proceedings of the National Academy of Sciences of the United States of America, vol. 93, no. 7, pp. 3043-3047, 1996.

[40] A. S. Maisel and M. C. Michel, " $\beta$-adrenoceptor control of immune function in congestive heart failure," British Journal of Clinical Pharmacology, vol. 30, supplement S1, pp. 49S-53S, 1990.

[41] K. Wallenius, J. Jansson, and V. Wallenius, "The therapeutic potential of interleukin-6 in treating obesity," Expert Opinion on Biological Therapy, vol. 3, no. 7, pp. 1061-1070, 2003.

[42] K. T. Uysal, S. M. Wiesbrock, M. W. Marino, and G. S. Hotamisligil, "Protection from obesity-induced insulin resistance in mice lacking TNF- $\alpha$ function," Nature, vol. 389, no. 6651, pp. 610-614, 1997.

[43] M. Bala, A. Kopp, S. Wurm, C. Büchler, J. Schölmerich, and A. Schäffler, "Type 2 diabetes and lipoprotein metabolism affect LPS-induced cytokine and chemokine release in primary human monocytes," Experimental and Clinical Endocrinology and Diabetes, vol. 119, no. 6, pp. 370-376, 2011.

[44] N. Nishitani and H. Sakakibara, "Relationship of obesity to job stress and eating behavior in male Japanese workers," International Journal of Obesity, vol. 30, no. 3, pp. 528-533, 2006.

[45] N. M. Petry, D. Barry, R. H. Pietrzak, and J. A. Wagner, "Overweight and obesity are associated with psychiatric disorders: results from the national epidemiologic survey on alcohol and related conditions," Psychosomatic Medicine, vol. 70, no. 3, pp. 288-297, 2008

[46] A. J. Stunkard, M. S. Faith, and K. C. Allison, "Depression and obesity," Biological Psychiatry, vol. 54, no. 3, pp. 330-337, 2003.

[47] M. K. Valtonen, D. E. Laaksonen, J. A. Laukkanen et al., "Lowgrade inflammation and depressive symptoms as predictors of abdominal obesity," Scandinavian Journal of Public Health, vol. 40, no. 7, pp. 674-680, 2012.

[48] P. Björntorp, "Do stress reactions cause abdominal obesity and comorbidities?" Obesity Reviews, vol. 2, no. 2, pp. 73-86, 2001.

[49] E. S. Epel, B. McEwen, T. Seeman et al., "Stress and body shape: stress-induced cortisol secretion is consistently greater among women with central fat," Psychosomatic Medicine, vol. 62, no. 5, pp. 623-632, 2000.

[50] S. Benson, P. C. Arck, S. Tan et al., "Effects of obesity on neuroendocrine, cardiovascular, and immune cell responses to acute psychosocial stress in premenopausal women," Psychoneuroendocrinology, vol. 34, no. 2, pp. 181-189, 2009. 
[51] R. Rosmond, M. F. Dallman, and P. Björntorp, "Stress-related cortisol secretion in men: relationships with abdominal obesity and endocrine, metabolic and hemodynamic abnormalities," Journal of Clinical Endocrinology and Metabolism, vol. 83, no. 6, pp. 1853-1859, 1998.

[52] G. E. Alvarez, S. D. Beske, T. P. Ballard, and K. P. Davy, "Sympathetic neural activation in visceral obesity," Circulation, vol. 106, no. 20, pp. 2533-2536, 2002.

[53] G. Grassi, G. Seravalle, B. M. Cattaneo et al., "Sympathetic activation in obese normotensive subjects," Hypertension, vol. 25, no. 4, pp. 560-563, 1995.

[54] M. A. van Baak, "The peripheral sympathetic nervous system in human obesity," Obesity Reviews, vol. 2, no. 1, pp. 3-14, 2001.

[55] C. J. Huang, J. K. Stewart, R. L. Franco et al., "LPS-stimulated tumor necrosis factor-alpha and interleukin-6 mRNA and cytokine responses following acute psychological stress," Psychoneuroendocrinology, vol. 36, no. 10, pp. 1553-1561, 2011.

[56] M. P. Yeager, A. J. Rassias, M. P. Fillinger et al., "Cortisol antiinflammatory effects are maximal at postoperative plasma concentrations," Critical Care Medicine, vol. 33, no. 7, pp. 1507-1512, 2005.

[57] P. H. Wirtz, U. Ehlert, L. Emini, and T. Suter, "Higher body mass index (BMI) is associated with reduced glucocorticoid inhibition of inflammatory cytokine production following acute psychosocial stress in men," Psychoneuroendocrinology, vol. 33, no. 8, pp. 1102-1110, 2008.

[58] G. Haskó and C. Szabó, "Regulation of cytokine and chemokine production by transmitters and co-transmitters of the autonomic nervous system," Biochemical Pharmacology, vol. 56, no. 9, pp. 1079-1087, 1998

[59] D. M. Nance and V. M. Sanders, "Autonomic innervation and regulation of the immune system (1987-2007)," Brain, Behavior, and Immunity, vol. 21, no. 6, pp. 736-745, 2007.

[60] V. M. Sanders and R. H. Straub, "Norepinephrine, the $\beta$ adrenergic receptor, and immunity," Brain, Behavior, and Immunity, vol. 16, no. 4, pp. 290-332, 2002.

[61] B. H. Yu, J. E. Dimsdale, and P. J. Mills, "Psychological states and lymphocyte $\beta$-Adrenergic receptor responsiveness," Neuropsychopharmacology, vol. 21, no. 1, pp. 147-152, 1999.

[62] E. C. Suarez, A. D. Shiller, C. M. Kuhn, S. Schanberg, R. B. Williams Jr., and E. A. Zimmermann, "The relationship between hostility and $\beta$-adrenergic receptor physiology in healthy young males," Psychosomatic Medicine, vol. 59, no. 5, pp. 481-487, 1997.

[63] G. Merlino, R. Scaglione, S. Paterna et al., "Lymphocyte betaadrenergic receptors in young subjects with peripheral or central obesity: relationship with central haemodynamics and left ventricular function," European Heart Journal, vol. 15, no. 6, pp. 786-792, 1994.

[64] J. R. Sowers, L. A. Whitfield, and R. A. Catania, "Role of the sympathetic nervous system in blood pressure maintenance in obesity," Journal of Clinical Endocrinology and Metabolism, vol. 54, no. 6, pp. 1181-1186, 1982.

[65] S. G. Wannamethee, J. Tchernova, P. Whincup et al., "Plasma leptin: associations with metabolic, inflammatory and haemostatic risk factors for cardiovascular disease," Atherosclerosis, vol. 191, no. 2, pp. 418-426, 2007.

[66] A. Bouloumié, T. Marumo, M. Lafontan, and R. Busse, "Leptin induces oxidative stress in human endothelial cells," FASEB Journal, vol. 13, no. 10, pp. 1231-1238, 1999.

[67] R. Otsuka, H. Yatsuya, K. Tamakoshi, K. Matsushita, K. Wada, and H. Toyoshima, "Perceived psychological stress and serum leptin concentrations in Japanese men," Obesity, vol. 14, no. 10, pp. 1832-1838, 2006.

[68] L. Brydon, C. E. Wright, K. O’Donnell, I. Zachary, J. Wardle, and A. Steptoe, "Stress-induced cytokine responses and central adiposity in young women," International Journal of Obesity, vol. 32, no. 3, pp. 443-450, 2008.

[69] D. E. R. Warburton, C. W. Nicol, and S. S. D. Bredin, "Health benefits of physical activity: the evidence," Canadian Medical Association Journal, vol. 174, no. 6, pp. 801-809, 2006.

[70] J. H. Wilmore, "Alterations in strength, body composition and anthropometric measurements consequent to a 10 week weight training program," Medicine and Science in Sports and Exercise, vol. 6, no. 2, pp. 133-138, 1974.

[71] K. E. Yarasheski, J. A. Campbell, K. Smith, M. J. Rennie, J. O. Holloszy, and D. M. Bier, "Effect of growth hormone and resistance exercise on muscle growth in young men," American Journal of Physiology-Endocrinology and Metabolism, vol. 262, no. 3, pp. E261-E267, 1992.

[72] L. H. Colbert, M. Visser, E. M. Simonsick et al., "Physical activity, exercise, and inflammatory markers in older adults: findings from the health, aging and body composition study," Journal of the American Geriatrics Society, vol. 52, no. 7, pp. 1098-1104, 2004.

[73] K. J. Stewart, "Role of exercise training on cardiovascular disease in persons who have type 2 diabetes and hypertension," Cardiology Clinics, vol. 22, no. 4, pp. 569-586, 2004.

[74] H. Selye, "Stress and the general adaptation syndrome," British Medical Journal, vol. 1, no. 4667, pp. 1383-1392, 1950.

[75] J. M. DiPenta, J. Green-Johnson, and R. J. L. Murphy, "Natural killer cells and exercise training in the elderly: a review," Canadian Journal of Applied Physiology, vol. 29, no. 4, pp. 419443, 2004.

[76] M. L. Kohut and D. S. Senchina, "Reversing age-associated immunosenescence via exercise," Exercise Immunology Review, vol. 10, pp. 6-41, 2004.

[77] R. Starkie, S. R. Ostrowski, S. Jauffred, M. Febbraio, and B. K. Pedersen, "Exercise and IL-6 infusion inhibit endotoxininduced TNF-alpha production in humans," The FASEB Journal, vol. 17, no. 8, pp. 884-886, 2003.

[78] R. Jankord and B. Jemiolo, "Influence of physical activity on serum IL-6 and IL-10 levels in healthy older men," Medicine and Science in Sports and Exercise, vol. 36, no. 6, pp. 960-964, 2004.

[79] C. Kasapis and P. D. Thompson, "The effects of physical activity on serum C-reactive protein and inflammatory markers: a systematic review," Journal of the American College of Cardiology, vol. 45, no. 10, pp. 1563-1569, 2005.

[80] A. Steptoe, J. Wardle, R. Fuller et al., "Leisure-time physical exercise: prevalence, attitudinal correlates, and behavioral correlates among young Europeans from 21 countries," Preventive Medicine, vol. 26, no. 6, pp. 845-854, 1997.

[81] K. Nosaka, K. Sakamoto, M. Newton, and P. Sacco, "The repeated bout effect of reduced-load eccentric exercise on elbow flexor muscle damage," European Journal of Applied Physiology, vol. 85, no. 1-2, pp. 34-40, 2001.

[82] H. Selye, The Stress of Life, The McGraw-Hill Companies, Columbus, Ohio, USA, 1984.

[83] L. L. Smith, "Cytokine hypothesis of overtraining: a physiological adaptation to excessive stress?" Medicine and Science in Sports and Exercise, vol. 32, no. 2, pp. 317-331, 2000.

[84] C. Janeway, P. Travers, M. Walport et al., Immunobiology, Garland, New York, NY, USA, 2001. 
[85] G. O. McCaulley, J. M. McBride, P. Cormie et al., "Acute hormonal and neuromuscular responses to hypertrophy, strength and power type resistane exercise," European Journal of Applied Physiology, vol. 105, no. 5, pp. 695-704, 2009.

[86] K. Hakkinen, A. Pakarinen, M. Alen, H. Kauhanen, and P. V. Komi, "Neuromuscular and hormonal adaptations in athletes to strength training in two years," Journal of Applied Physiology, vol. 65, no. 6, pp. 2406-2412, 1988.

[87] G. J. Bagby, D. E. Sawaya, L. D. Crouch, and R. E. Shepherd, "Prior exercise suppresses the plasma tumor necrosis factor response to bacterial lipopolysaccharide," Journal of Applied Physiology, vol. 77, no. 3, pp. 1542-1547, 1994.

[88] K. Nosaka and P. M. Clarkson, "Changes in indicators of inflammation after eccentric exercise of the elbow flexors," Medicine and Science in Sports and Exercise, vol. 28, no. 8, pp. 953-961, 1996.

[89] G. S. Hotamisligil and B. M. Spiegelman, "Tumor necrosis factor alpha: a key component of the obesity-diabetes link," Diabetes, vol. 43, no. 11, pp. 1271-1278, 1994.

[90] G. S. Hotamisligil, P. Arner, J. F. Caro, R. L. Atkinson, and B. M. Spiegelman, "Increased adipose tissue expression of tumor necrosis factor- $\alpha$ in human obesity and insulin resistance," Journal of Clinical Investigation, vol. 95, no. 5, pp. 2409-2415, 1995.

[91] G. S. Hotamisligil, "Inflammatory pathways and insulin action," International Journal of Obesity, vol. 27, supplement 3, pp. S53S55, 2003.

[92] F. Mattusch, B. Dufaux, O. Heine, I. Mertens, and R. Rost, "Reduction of the plasma concentration of C-reactive protein following nine months of endurance training," International Journal of Sports Medicine, vol. 21, no. 1, pp. 21-24, 2000.

[93] J. A. Woods, V. J. Vieira, and K. T. Keylock, "Exercise, Inflammation, and Innate Immunity," Immunology and Allergy Clinics of North America, vol. 29, no. 2, pp. 381-393, 2009.

[94] N. Kondo, M. Nomura, Y. Nakaya, S. Ito, and T. Ohguro, "Association of inflammatory marker and highly sensitive C-reactive protein with aerobic exercise capacity, maximum oxygen uptake and insulin resistance in healthy middle-aged volunteers," Circulation Journal, vol. 69, no. 4, pp. 452-457, 2005.

[95] P. Balagopal, D. George, N. Patton et al., "Lifestyle-only intervention attenuates the inflammatory state associated with obesity: a randomized controlled study in adolescents," Journal of Pediatrics, vol. 146, no. 3, pp. 342-348, 2005.

[96] A. S. Kelly, R. J. Wetzsteon, D. R. Kaiser, J. Steinberger, A. J. Bank, and D. R. Dengel, "Inflammation, insulin, and endothelial function in overweight children and adolescents: the role of exercise," Journal of Pediatrics, vol. 145, no. 6, pp. 731-736, 2004.

[97] K. Okita, H. Nishijima, T. Murakami et al., "Can exercise training with weight loss lower serum C-reactive protein levels?” Arteriosclerosis, Thrombosis, and Vascular Biology, vol. 24, no. 10, pp. 1868-1873, 2004.

[98] T. J. Marcell, K. A. McAuley, T. Traustadóttir, and P. D. Reaven, "Exercise training is not associated with improved levels of Creactive protein or adiponectin," Metabolism, vol. 54, no. 4, pp. 533-541, 2005.

[99] K. Esposito, A. Pontillo, C. Di Palo et al., "Effect of weight loss and lifestyle changes on vascular inflammatory markers in obese women: a randomized trial," Journal of the American Medical Association, vol. 289, no. 14, pp. 1799-1804, 2003.

[100] R. Glaser and J. K. Kiecolt-Glaser, "Stress-induced immune dysfunction: implications for health," Nature Reviews Immunology, vol. 5, no. 3, pp. 243-251, 2005.
[101] S. Hickling, J. Hung, M. Knuiman, M. Divitini, and J. Beilby, "Are the associations between diet and C-reactive protein independent of obesity?" Preventive Medicine, vol. 47, no. 1, pp. 71-76, 2008.

[102] L. Fontana, "Calorie restriction and cardiometabolic health," European Journal of Cardiovascular Prevention and Rehabilitation, vol. 15, no. 1, pp. 3-9, 2008.

[103] S. Dickinson, D. P. Hancock, P. Petocz, A. Ceriello, and J. BrandMiller, "High-glycemic index carbohydrate increases nuclear factor- $\kappa \mathrm{B}$ activation in mononuclear cells of young, lean healthy subjects1-3," American Journal of Clinical Nutrition, vol. 87, no. 5, pp. 1188-1193, 2008.

[104] P. Kallio, M. Kolehmainen, D. E. Laaksonen et al., "Inflammation markers are modulated by responses to diets differing in postprandial insulin responses in individuals with the metabolic syndrome," American Journal of Clinical Nutrition, vol. 87, no. 5, pp. 1497-1503, 2008.

[105] J. Galgani, C. Aguirre, and E. Díaz, "Acute effect of meal glycemic index and glycemic load on blood glucose and insulin responses in humans," Nutrition Journal, vol. 5, no. 1, p. 22, 2006.

[106] A. Garg, S. M. Grundy, and R. H. Unger, "Comparison of effects of high and low carbohydrate diets on plasma lipoproteins and insulin sensitivity in patients with mild NIDDM," Diabetes, vol. 41, no. 10, pp. 1278-1285, 1992.

[107] C. E. Forsythe, S. D. Phinney, M. L. Fernandez et al., "Comparison of low fat and low carbohydrate diets on circulating fatty acid composition and markers of inflammation," Lipids, vol. 43, no. 1, pp. 65-77, 2008.

[108] K. D. O’Brien, B. J. Brehm, R. J. Seeley et al., "Diet-induced weight loss is associated with decreases in plasma serum amyloid A and C-reactive protein independent of dietary macronutrient composition in obese subjects," Journal of Clinical Endocrinology and Metabolism, vol. 90, no. 4, pp. 2244-2249, 2005.

[109] S. Kasim-Karakas, A. Tsodikov, U. Singh, and I. Jialal, "Responses of inflammatory markers to a low-fat, highcarbohydrate diet: effects of energy intake," American Journal of Clinical Nutrition, vol. 83, no. 4, pp. 774-779, 2006.

[110] C. J. North, C. S. Venter, and J. C. Jerling, "The effects of dietary fibre on C-reactive protein, an inflammation marker predicting cardiovascular disease," European Journal of Clinical Nutrition, vol. 63, no. 8, pp. 921-933, 2009.

[111] D. E. King, B. M. Egan, R. F. Woolson, A. G. Mainous III, Y. Al-Solaiman, and A. Jesri, "Effect of a high-fiber diet vs a fiber-supplemented diet on C-reactive protein level," Archives of Internal Medicine, vol. 167, no. 5, pp. 502-506, 2007.

[112] P. D. Schley and C. J. Field, "The immune-enhancing effects of dietary fibres and prebiotics," British Journal of Nutrition, vol. 87, supplement 3, pp. S221-S230, 2002.

[113] S. Bo, G. Ciccone, S. Guidi et al., "Diet or exercise: what is more effective in preventing or reducing metabolic alterations?" European Journal of Endocrinology, vol. 159, no. 6, pp. 685-691, 2008.

[114] E. Lopez-Garcia, M. B. Schulze, T. T. Fung et al., "Major dietary patterns are related to plasma concentrations of markers of inflammation and endothelial dysfunction," The American Journal of Clinical Nutrition, vol. 80, no. 4, pp. 1029-1035, 2004.

[115] R. Clarke, M. Shipley, J. Armitage, R. Collins, and W. Harris, "Plasma phospholipid fatty acids and CHD in older men: Whitehall study of London civil servants," British Journal of Nutrition, vol. 102, no. 2, pp. 279-284, 2009. 
[116] S. Arya, S. Isharwal, A. Misra et al., "C-reactive protein and dietary nutrients in urban Asian Indian adolescents and young adults," Nutrition, vol. 22, no. 9, pp. 865-871, 2006.

[117] S. Poppitt, G. F. Keogh, F. E. Lithander et al., "Postprandial response of adiponectin, interleukin-6, tumor necrosis factor$\alpha$, and C-reactive protein to a high-fat dietary load," Nutrition, vol. 24, no. 4, pp. 322-329, 2008.

[118] G. Fredrikson, B. Hedblad, J. Nilsson, R. Alm, G. Berglund, and J. Nilsson, "Association between diet, lifestyle, metabolic cardiovascular risk factors, and plasma C-reactive protein levels," Metabolism, vol. 53, no. 11, pp. 1436-1442, 2004.

[119] D. Mozaffarian, T. Pischon, S. E. Hankinson et al., "Dietary intake of trans fatty acids and systemic inflammation in women," American Journal of Clinical Nutrition, vol. 79, no. 4, pp. 606-612, 2004.

[120] D. Kromhout, A. Menotti, B. Bloemberg et al., "Dietary saturated and trans fatty acids and cholesterol and 25-year mortality from coronary heart disease: the Seven Countries Study," Preventive Medicine, vol. 24, no. 3, pp. 308-315, 1995.

[121] N. D. Riediger, R. A. Othman, M. Suh, and M. H. Moghadasian, "A systemic review of the roles of n-3 fatty acids in health and disease," Journal of the American Dietetic Association, vol. 109, no. 4, pp. 668-679, 2009.

[122] M. De Lorgeril, "Essential polyunsaturated fatty acids, inflammation, atherosclerosis and cardiovascular diseases," SubCellular Biochemistry, vol. 42, pp. 283-297, 2007.

[123] A. N. Margioris, "Fatty acids and postprandial inflammation," Current Opinion in Clinical Nutrition and Metabolic Care, vol. 12, no. 2, pp. 129-137, 2009.

[124] S. Devaraj, S. Kasim-Karakas, and I. Jialal, "The effect of weight loss and dietary fatty acids on inflammation," Current Atherosclerosis Reports, vol. 8, no. 6, pp. 477-486, 2006.

[125] A. Basu, S. Devaraj, and I. Jialal, "Dietary factors that promote or retard inflammation," Arteriosclerosis, Thrombosis, and Vascular Biology, vol. 26, no. 5, pp. 995-1001, 2006.

[126] Y. Jiménez-Gómez, J. López-Miranda, L. M. Blanco-Colio et al., "Olive oil and walnut breakfasts reduce the postprandial inflammatory response in mononuclear cells compared with a butter breakfast in healthy men," Atherosclerosis, vol. 204, no. 2, pp. e70-e76, 2009.

[127] R. M. van Dam, L. Grievink, M. C. Ocké, and E. J. M. Feskens, "Patterns of food consumption and risk factors for cardiovascular disease in the general Dutch population," American Journal of Clinical Nutrition, vol. 77, no. 5, pp. 1156-1163, 2003.

[128] J. M. Hodgson, N. C. Ward, V. Burke, L. J. Beilin, and I. B. Puddey, "Increased lean red meat intake does not elevate markers of oxidative stress and inflammation in humans," Journal of Nutrition, vol. 137, no. 2, pp. 363-367, 2007.

[129] M. B. Schulze, J. E. Manson, W. C. Willett, and F. B. Hu, "Processed meat intake and incidence of Type 2 diabetes in younger and middle-aged women," Diabetologia, vol. 46, no. 11, pp. 1465-1473, 2003.

[130] J. Holmer-Jensen, T. Karhu, L. S. Mortensen, S. B. Pedersen, K. Herzig, and K. Hermansen, "Differential effects of dietary protein sources on postprandial low-grade inflammation after a single high fat meal in obese non-diabetic subjects," Nutrition Journal, vol. 10, no. 1, p. 115, 2011.

[131] A. Nanri, D. Yoshida, T. Yamaji, T. Mizoue, R. Takayanagi, and S. Kono, "Dietary patterns and C-reactive protein in Japanese men and women," American Journal of Clinical Nutrition, vol. 87, no. 5, pp. 1488-1496, 2008.
[132] A. Esmaillzadeh and L. Azadbakht, "Home use of vegetable oils, markers of systemic inflammation, and endothelial dysfunction among women," American Journal of Clinical Nutrition, vol. 88, no. 4, pp. 913-921, 2008.

[133] M. M. Nasca, J. Zhou, and F. K. Welty, "Effect of soy nuts on adhesion molecules and markers of inflammation in hypertensive and normotensive postmenopausal women," American Journal of Cardiology, vol. 102, no. 1, pp. 84-86, 2008.

[134] A. Steptoe, E. L. Gibson, R. Vuononvirta et al., "The effects of chronic tea intake on platelet activation and inflammation: a double-blind placebo controlled trial," Atherosclerosis, vol. 193, no. 2, pp. 277-282, 2007.

[135] K. C. Ock, S. Chung, K. J. Claycombe, and W. O. Song, "Serum C-reactive protein concentrations are inversely associated with dietary flavonoid intake in U.S. adults," Journal of Nutrition, vol. 138, no. 4, pp. 753-760, 2008.

[136] J. Walston, Q. Xue, R. D. Semba et al., "Serum antioxidants, inflammation, and total mortality in older women," American Journal of Epidemiology, vol. 163, no. 1, pp. 18-26, 2006.

[137] W. van Herpen-Broekmans, I. Klöpping-Ketelaars, B. Michiel et al., "Serum carotenoids and vitamins in relation to markers of endothelial," European Journal of Epidemiology, vol. 19, no. 10, pp. 915-921, 2004.

[138] S. A. Chacko, Y. Song, L. Nathan et al., "Relations of dietary magnesium intake to biomarkers of inflammation and endothelial dysfunction in an ethnically diverse cohort of postmenopausal women," Diabetes Care, vol. 33, no. 2, pp. 304-310, 2010.

[139] R. F. Grimble, "Effect of antioxidative vitamins on immune function with clinical applications," International Journal for Vitamin and Nutrition Research, vol. 67, no. 5, pp. 312-320, 1997.

[140] A. H. Lichtenstein, L. J. Appel, M. Brands et al., "Diet and lifestyle recommendations revision 2006: a scientific statement from the American heart association nutrition committee," Circulation, vol. 114, no. 1, pp. 82-96, 2006.

[141] Y. Nakamura, Y. Ueno, S. Tamaki et al., "Fish consumption and early atherosclerosis in middle-aged men," Metabolism, vol. 56, no. 8, pp. 1060-1064, 2007.

[142] B. de Roos, A. Geelen, K. Ross et al., "Identification of potential serum biomarkers of inflammation and lipid modulation that are altered by fish oil supplementation in healthy volunteers," Proteomics, vol. 8, no. 10, pp. 1965-1974, 2008.

[143] N. T. Luu, J. Madden, P. C. Calder et al., "Dietary supplementation with fish oil modifies the ability of human monocytes to induce an inflammatory response," Journal of Nutrition, vol. 137, no. 12, pp. 2769-2774, 2007.

[144] S. L. Seierstad, I. Seljeflot, O. Johansen et al., "Dietary intake of differently fed salmon; the influence on markers of human atherosclerosis," European Journal of Clinical Investigation, vol. 35, no. 1, pp. 52-59, 2005.

[145] X. Gao, O. I. Bermudez, and K. L. Tucker, "Plasma C-reactive protein and homocysteine concentrations are related to frequent fruit and vegetable intake in hispanic and non-hispanic white elders," Journal of Nutrition, vol. 134, no. 4, pp. 913-918, 2004.

[146] B. Watzl, S. E. Kulling, J. Möseneder, S. W. Barth, and A. Bub, "A 4-wk intervention with high intake of carotenoidrich vegetables and fruit reduces plasma C-reactive protein in healthy, nonsmoking men," American Journal of Clinical Nutrition, vol. 82, no. 5, pp. 1052-1058, 2005. 
[147] G. D. Stoner, L. Wang, N. Zikri et al., "Cancer prevention with freeze-dried berries and berry components," Seminars in Cancer Biology, vol. 17, no. 5, pp. 403-410, 2007.

[148] Y. Zhu, W. Ling, H. Guo H et al., "Anti-inflammatory effect of purified dietary anthocyanin in adults with hypercholesterolemia: a randomized controlled trial," Nutrition, Metabolism \& Cardiovascular Diseases, vol. 23, no. 9, pp. 843-849, 2013.

[149] H. R. Maurer, "Bromelain: biochemistry, pharmacology and medical use," Cellular and Molecular Life Sciences, vol. 58, no. 9, pp. 1234-1245, 2001.

[150] S. Müller, R. März, M. Schmolz, B. Drewelow, K. Eschmann, and P. Meiser, "Placebo-controlled randomized clinical trial on the immunomodulating activities of low- and high-dose bromelain after oral administration-new evidence on the antiinflammatory mode of action of bromelain," Phytotherapy Research, vol. 27, no. 2, pp. 199-204, 2012.

[151] G. Klein and W. Kullich, "Short-term treatment of painful osteoarthritis of the knee with oral enzymes. A randomised, double-blind study versus diclofenac," Clinical Drug Investigation, vol. 19, no. 1, pp. 15-23, 2000.

[152] H. Li, Y. Huang, C. Zhang et al., "Epigallocathechin-3 gallate inhibits cardiac hypertrophy through blocking reactive oxidative species-dependent and -independent signal pathways," Free Radical Biology \& Medicine, vol. 40, no. 10, pp. 1756-1775, 2006.

[153] H. Sung, W. Min, W. Lee et al., "The effects of green tea ingestion over four weeks on atherosclerotic markers," Annals of Clinical Biochemistry, vol. 42, no. 4, pp. 292-297, 2005.

[154] W. Lee, W. Min, S. Chun et al., "Long-term effects of green tea ingestion on atherosclerotic biological markers in smokers," Clinical Biochemistry, vol. 38, no. 1, pp. 84-87, 2005.

[155] L. F. Andersen, D. R. Jacobs, M. H. Carlsen, and R. Blomhoff, "Consumption of coffee is associated with reduced risk of death attributed to inflammatory and cardiovascular diseases in the Iowa Women's Health Study," American Journal of Clinical Nutrition, vol. 83, no. 5, pp. 1039-1046, 2006.

[156] A. Zampelas, D. B. Panagiotakos, C. Pitsavos, C. Chrysohoou, and C. Stefanadis, "Associations between coffee consumption and inflammatory markers in healthy persons: the ATTICA study," American Journal of Clinical Nutrition, vol. 80, no. 4, pp. 862-867, 2004.

[157] C. J. Womack, M. J. Saunders, M. K. Bechtel et al., "The influence of a CYP1A2 polymorphism on the ergogenic effects of caffeine," Journal of the International Society of Sports Nutrition, vol. 9, no. 7, p. 7, 2012.

[158] X. Lv, Z. Chen, J. Li et al., "Caffeine protects against alcoholic liver injury by attenuating inflammatory response and oxidative stress," Inflammation Research, vol. 59, no. 8, pp. 635-645, 2010.

[159] J. H. O'Keefe, K. A. Bybee, and C. J. Lavie, "Alcohol and cardiovascular health. The razor-sharp double-edged sword," Journal of the American College of Cardiology, vol. 50, no. 11, pp. 1009-1014, 2007.

[160] J. K. Pai, S. E. Hankinson, R. Thadhani, N. Rifai, T. Pischon, and E. B. Rimm, "Moderate alcohol consumption and lower levels of inflammatory markers in US men and women," Atherosclerosis, vol. 186, no. 1, pp. 113-120, 2006.

[161] E. Sacanella, M. Vázquez-Agell, M. P. Mena et al., "Downregulation of adhesion molecules and other inflammatory biomarkers after moderate wine consumption in healthy women: a randomized trial," American Journal of Clinical Nutrition, vol. 86, no. 5, pp. 1463-1469, 2007.

[162] E. B. Rimm, A. Klatsky, D. Grobbee, and M. J. Stampfer, "Review of moderate alcohol consumption and reduced risk of coronary heart disease: is the effect due to beer, wine, or spirits?" British Medical Journal, vol. 312, no. 7033, pp. 731-736, 1996.

[163] J. R. Martínez Alvarez, V. V. Bellés, A. B. López-Jaén et al., "Effects of alcohol-free beer on lipid profile and parameters of oxidative stress and inflammation in elderly women," Nutrition, vol. 25, no. 2, pp. 182-187, 2009.

[164] L. C. Tapsell, I. Hemphill, L. Cobiac et al., "Health benefits of herbs and spices: the past, the present, the future," The Medical Journal of Australia, vol. 185, supplement 4, pp. S4-S24, 2006.

[165] USDA, Agricultural Fact Book, chapter 2, United States Department of Agriculture, Washington, DC, USA, 2002.

[166] L. Galland, "Diet and inflammation," Nutrition in Clinical Practice, vol. 25, no. 6, pp. 634-640, 2010. 


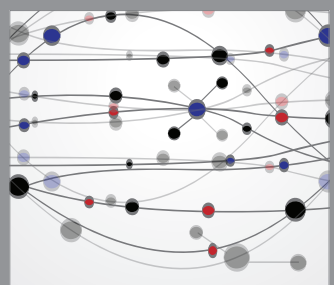

The Scientific World Journal
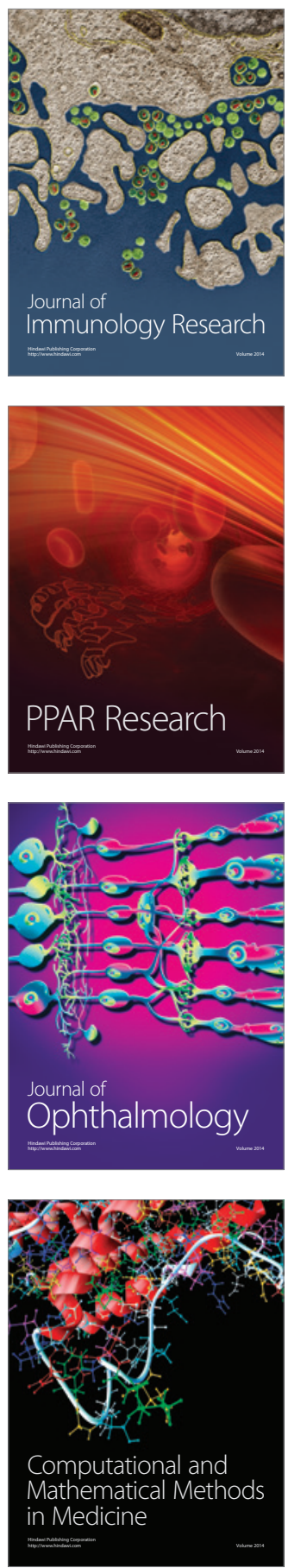

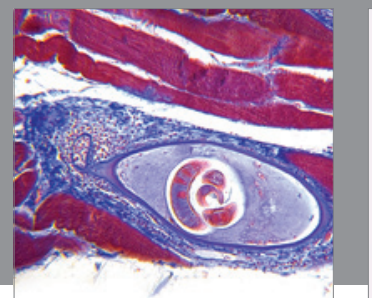

Gastroenterology

Research and Practice
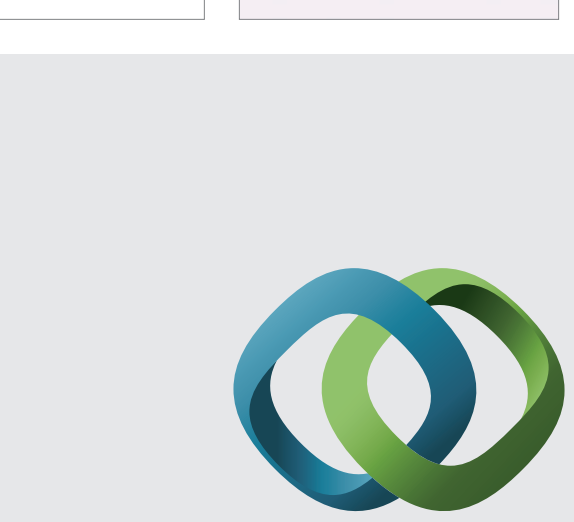

\section{Hindawi}

Submit your manuscripts at

http://www.hindawi.com
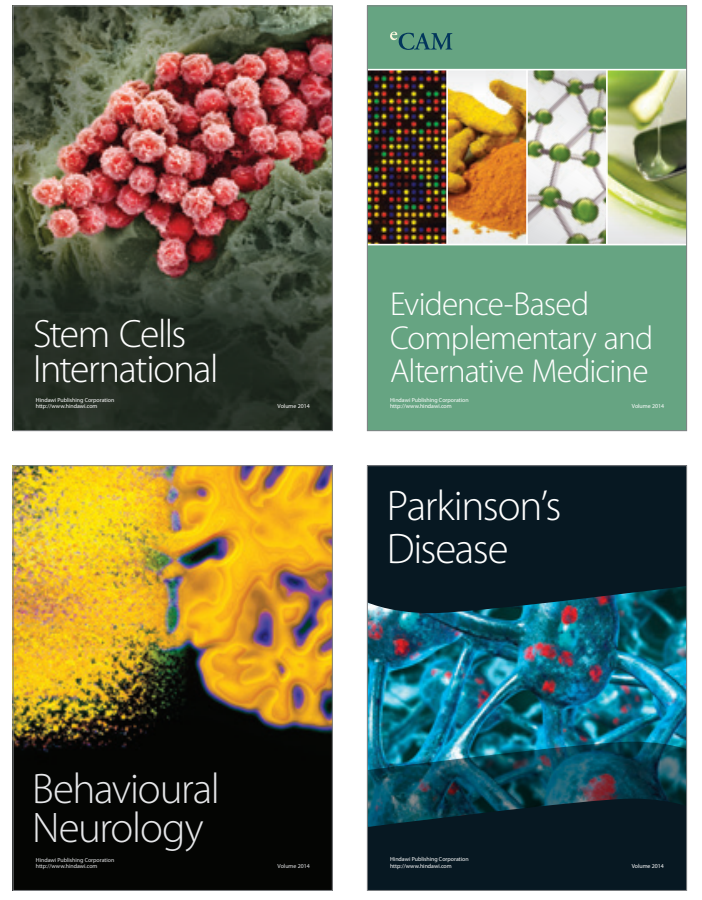
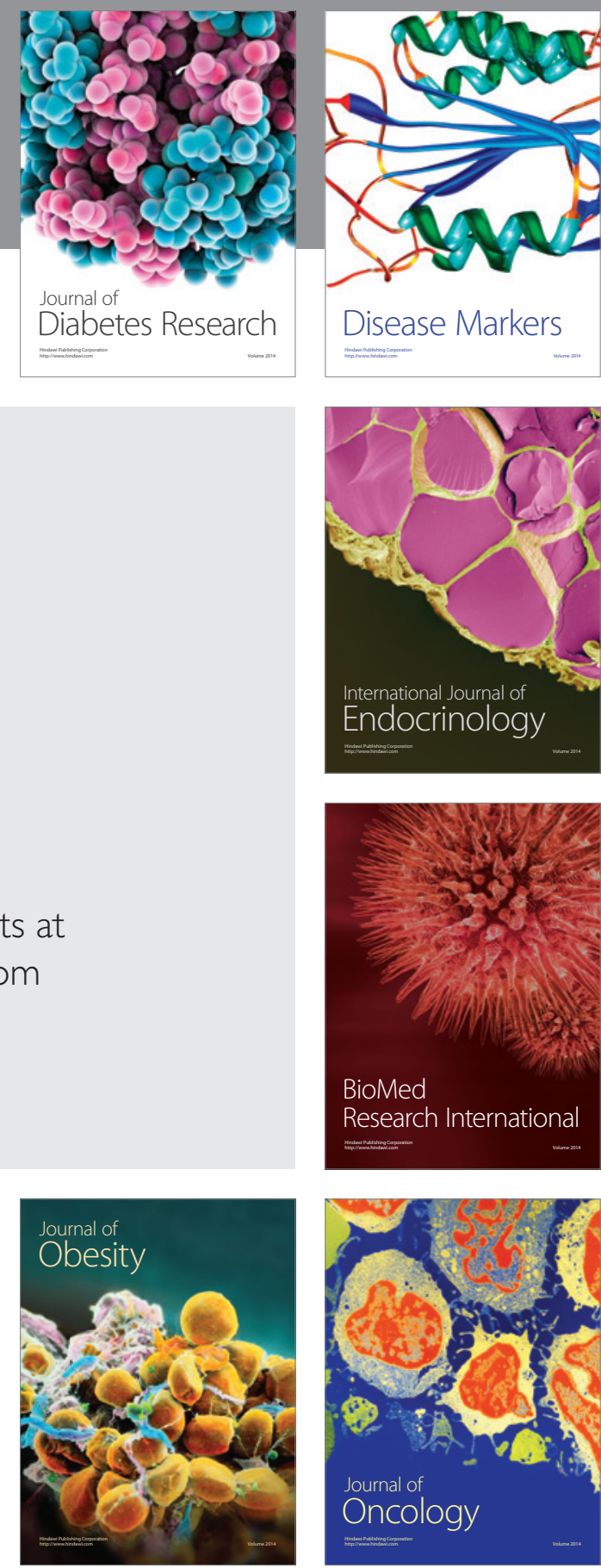

Disease Markers
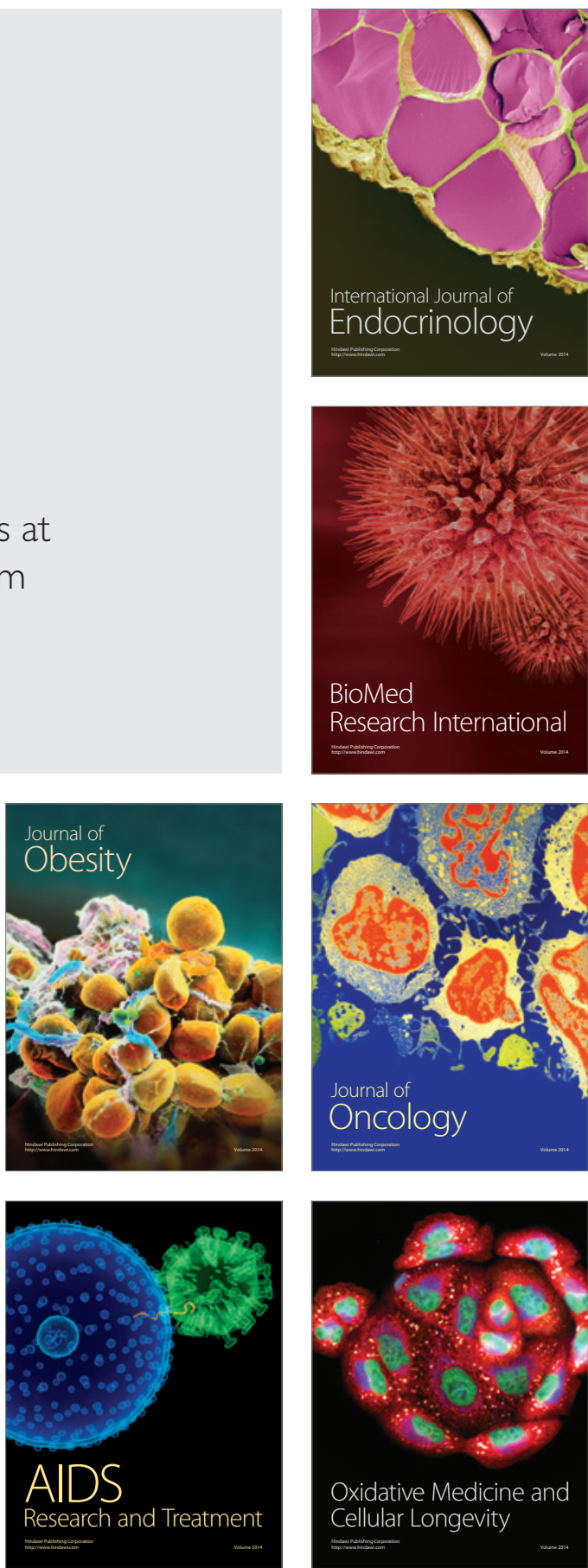